\title{
Regular Education Teachers' Attitudes towards Inclusion in 0 man
}

\author{
Jalal H. Hussien* \\ Ibrahim Al-Qaryouti \\ Madison Metropolitan School District, USA \\ Sultan Qaboos University, Oman
}

Received: 6/1/2014

Revised: 26/4/2014

Accepted: 22/5/2014

The objectives of the study were to investigate regular education teachers' attitudes towards inclusion and their educational setting preferences for teaching students with disabilities. In addition, the impact of teachers' gender and teaching experience on the attitudes towards inclusion were examined. Seven hundred three Omani regular education teachers participated in this study. The findings suggest that the Omani regular education teachers held neutral behavior, cognitive, and affective attitudes towards inclusion; and a small minority of teachers believed that full inclusion in regular education classrooms or resource rooms were the best educational settings for educating the students with disabilities in comparison with other educational settings. Finally, the results indicated that there were significant relationships between teachers' gender, teaching experience, and educational settings preference for educating students with disabilities and teachers' attitudes towards inclusion.

Keywords: attitudes, inclusion, teachers, Oman.

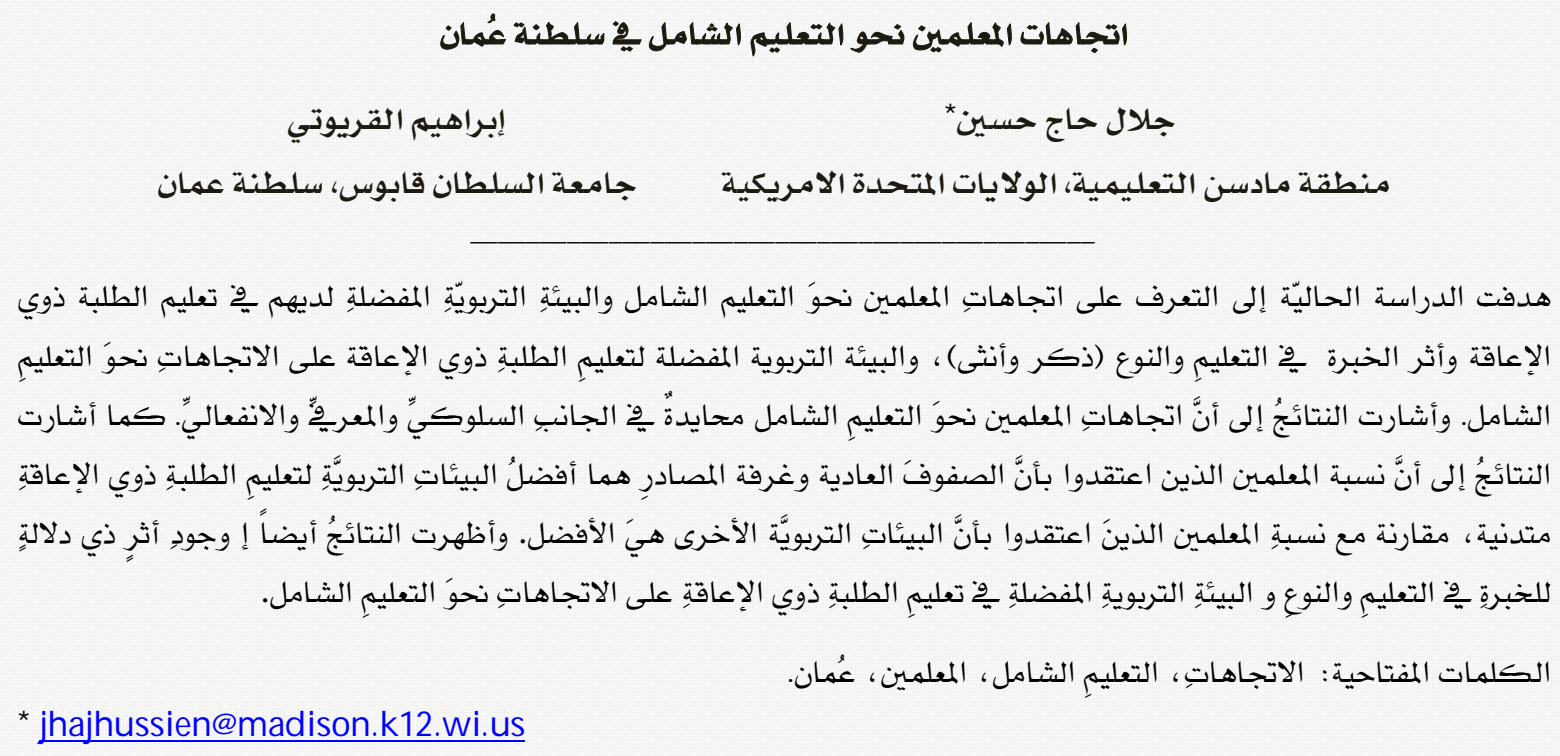


Inclusion refers to teaching students with disabilities in their neighborhood school within the regular classroom with their peers without disabilities (Rafferty, Boettcher, \& Griffin, 2001). Inclusive education became a global agenda when The United Nations endorsed the idea of 'Education for All' in 1990, and challenged all nations in 1994 to include students with disabilities in regular education environments with their peers. In 2006, Article 24 of the United Nations Convention on the Rights of Persons with Disabilities guarantees to the right of persons with disabilities an education in an inclusive educational setting. Most nations around the world accepted the challenge and committed themselves to an inclusive education by declaring laws and legislations that mandate the rights of students with disabilities to inclusive education. In 2008, the Welfare and Rehabilitation of Persons with Disabilities Act in Oman was issued by Royal Decree No. 63/ 2008. Furthermore, in the same year, the International A greement on the Rights of Persons with Disabilities was accepted by Royal Decree No. 121/ 2008.

Despite commitment and regulations, the implementation of inclusive education is a complicated process. Successful inclusive education requires restructuring the education system, establishing national policy and procedures that define and regulate teaching students with disabilities, allocating resources, creating accessible schools, and relying on competent teachers with positive attitudes. Regular education teachers play a critical role in the implementation of inclusive education. The success of inclusive education depends on the teachers' attitude (A hsan, Sharma \& Deppeler, 2012; A vramidis, Balyliss, \& Burden, 2000; A vramidis \& Norwich, 2002; Emam \& Mohamed, 2011; Sari, Celikoz \& Secer, 2009). The teacher's attitude is an important factor in determining the acceptance or the rejection of the students with disabilities, which impacts their social participation and academic performance in the regular classroom.

In spite of students with disabilities having rights, the opinions of educators vary significantly whether regular classroom is the best placement for educating students with all types of disabilities Bowman, 1986). Also, teachers' attitudes towards inclusion varies across nations, cultural values, level of training, number of students receiving services, and the existence of special education within the educational system (Leyser, Kapperman, \& Keller, 1994).

Teachers' attitudes towards inclusive education and the impact of teacher-related variables on their attitudes have been the focus of many studies. In addition, measuring teachers' attitudes towards inclusive education has been a concern (A. de Boer, 2012; A. de Boer, Timmerman, Pijl, \& Minnaert, 2012; Ernst, 2006).

With regard to teachers' attitudes towards inclusive education Scruggs and Mastropieri (1996) conducted a meta-analysis study on 28 studies published from 1958 to 1995. A total of 10,560 teachers, including 6,459 regular education teachers from the U.S.A., Australia, and Canada participated in the 28 studies. Their findings indicated that $53.4 \%$ support the concept of inclusion, $50.8 \%$ agreed that students with or without disabilities could benefit from inclusion experiences, and 33.3\% of regular education teachers agreed that the general education classroom was the best environment for students with disabilities; $81.6 \%$ of regular education teachers agreed that inclusion creates more work, and $48.7 \%$ would feel "imposed upon". The findings also indicated that regular education teachers' support for inclusion varies according to the type and severity of the disability.

A nother literature review by Avramidis and Norwich (2002) included studies relevant to teachers' attitudes published from 1984 to 2000. They cited two studies from the United States (Coates, 1989., Semmel et al., 1991) which indicated that regular education teachers did not express support for inclusion and they did not have a negative view of pullout programs. Also, they concluded that there is sufficient evidence that teachers have negative attitudes towards inclusive education for students with severe learning problems and be havioral difficulties. With regard to the impact of teachers' gender the findings were not conclusive; some researchers reported that female teachers express higher positive attitudes towards inclusion than male teachers. Other researchers reported that the effect of gender was not significant. Similarly, some researchers reported a significant negative relationship between years of teaching experience and their attitudes towards inclusion, 
while others reported no significant relationship between the two variables.

Ernst (2006) investigated the impact of regular education teachers' gender and teaching experience on their attitudes towards inclusive education. The sample involved 149 high school teachers from Connecticut, U.S.A. Her literature review indicated that the impact of teachers' gender and teaching experience on their attitudes towards inclusion were inconsistent. The findings of her study indicated that male teachers expressed more positive affective attitudes towards inclusion than the female teachers. In contrast, gender had no significant impact on their cognitive and behavior attitudes. Additionally, teachers' teaching experience had no significant impact on their cognitive, affective, and behavior attitudes.

De Boer, Pijlb, and Minnaerta (2011) (cited in Eagly \& Chaiken, 1993) reviewed studies relevant to regular education teachers' attitudes towards inclusion published between 1998 and 2008 according to the three-component theory. The authors found 396 articles; of these articles only 26 met the criteria set forth in the study. These studies represented samples of regular education teachers from 16 countries. The findings indicated none of the selected studies addressed the three components of attitudes; most of the studies focused on the cognitive component. In addition, the findings revealed that teachers showed negative, or were undecided in, their cognitive, affective, and behavior responses to inclusive education. The findings support that teachers with fewer years of teaching experience hold more positive attitudes towards inclusive education than teachers who have many years of teaching experience. However, the findings were inconsistent with regard to the impact of teachers' gender on their attitudes towards inclusive education. Finally, teachers showed more negative attitudes towards the inclusion of students with learning disabilities, AD/ HD and other behavior problems than towards the inclusion of students with physical disabilities and sensory impairments.

Despite the numerous studies of teachers' attitudes towards inclusion, there are many concerns regarding the instruments that have been used in measuring their attitudes. The literature review by Ernst (2006), and DeBoer, Timmerman, Pijl, \& Minnaert, (2012) and the present authors revealed the following: a) lack of definition of attitude and inclusion, b) lack of theory in developing the instrument, c) variation in the level of specificity among the instruments, d) variation in the number of the factor structure among the instruments, and e) many authors did not report evidence regarding the reliability and validity of the instruments used in measuring the attitudes.

In addition, De Boer, Timmerman, Pijl, \& Minnaert, (2012) reported that none of the selected studies they reviewed addressed the three components of attitudes (cognitive, be havior, \& affective); most of the studies focused on the cognitive component. Ernst (2006) found that one study (Avramidis and Norwich, 2002) addressed the three components based on Eagly \& Chaiken (1993) theoretical frame work; the present author found two studies (A vramidis and Norwich, 2002; Ernst, 2006 ) including the study found by Ernst, 2006.

In summary, all researchers agreed that the regular education teacher plays a major role in developing and implementing inclusive education. With regard to the regular teachers' attitudes towards inclusion the findings of the previous studies were not conclusive. Also, the impact of teachers' gender and teaching experience on their attitudes was not consistent. Finally, measuring attitudes remains a concern.

Further exploration of regular classroom teachers' attitudes towards inclusion, the impact of teachers' gender and teaching experience on their attitudes is still needed. In addition, there is a lack of research regarding teachers' attitudes towards inclusion in Oman. The aims of the current study were the following: a) to investigate the attitudes of regular education teachers towards inclusion, b) to examine the regular education teachers' educational settings preference for educating students with disabilities, c) to examine the effect of teachers' gender and teaching experience on attitudes towards inclusion, and d) to examine the impact of the regular education teacher educational settings preference for educating students with disabilities on their attitudes towards inclusion. 


\section{METHOD}

\section{Participants}

A total of 800 questionnaires were sent to the administrators of the public schools in Sultanate Oman in various directorates; 703 regular education teachers volunteered to complete the questionnaires. The sample involved 140 basic education- cycle one teachers, 236 basic education-cycle two teachers, and 325 post basic education- cycle teachers. Finally, the range of teaching experience among the participants varied from 1 to 30 years, the average being 8.38 years with a standard deviation of 4.97. The distribution of the sample according to directorate and gender is presented in Table 1.

Table 1

Sample distribution by province and gender

\begin{tabular}{lrr}
\hline Province & \multicolumn{2}{c}{ Gender } \\
\cline { 2 - 3 } & Male & Female \\
\hline Muscat & 192 & 212 \\
Al Batinah Janoob & 46 & 10 \\
Al Batinah Shamal & 37 & 41 \\
Al Dakhiliyah & 7 & 14 \\
Ash Sharqiyah Janoob & 0 & 5 \\
A sh Sharqiyah Shamal & 17 & 9 \\
Al Burimi & 8 & 8 \\
Al Dhirah & 8 & 4 \\
Dhofar & 25 & 34 \\
AL Wusta & 11 & 0 \\
Musandam & 8 & 7 \\
Total & 359 & 344 \\
\hline
\end{tabular}

\section{Measures}

Attitudes towards inclusion: This continuous variable was defined as participants' scores on each component of attitudes (cognitive, affective, and behavioral intentions) in the Attitudes Scale towards Inclusion (ASTI). The ASTI was designed by the authors to measure teachers' attitudes towards inclusion based on the definition of inclusion as teaching students with disabilities in regular neighborhood schools within the regular classrooms with their peers. Also, the scale was designed based on the conceptualization of attitudes as a tri-component evaluation consisting of cognitive, affective, and behavioral intentions.

Eagly \& Chaiken (1993) define attitude as tendencies to evaluate an entity with some degree of favor or disfavor, generally expressed in cognitive, affective, and behavioral responses. The cognitive response consists of thoughts and beliefs towards the attitude object. The affective response includes moods, feelings or emotions in relation to the attitude object. The behavioral response involves intentions or overt actions towards the attitude object.

The ASTI consisted of 19 items, seven items reflecting cognitive beliefs response, the second factor consisted of seven items reflecting behavior or intention, and the third factor consisted of five items reflecting affective re sponse. The participant's extent of the agree ment with each item was measured by a 3 point Likert scale (1 disagree, 2 agree, and 3 strongly agree).

The items' content validity was examined by four experts, among them two experts in measurement and psychometric theory and two experts in special education. The experts' review revealed that the items were written in clear and precise language and measured the components intended to be measured, confirming the content validity of the scale.

In addition, a principal components analysis was performed on 370 general education teachers' raw scores on 19 items. The results revealed that the three factors after rotation accounted for $66.92 \%$ of the total variance: $23.76 \%, 23.15 \%$, and $20.02 \%$, respectively. The 19 items loaded significantly in the three factors they were intended to measure. All values of the items loading were higher than .55 which exceeds the recommended cutoff value .30 (Costello \& Osborne, 2005).

Furthermore, test-retest reliability coefficients $(\mathrm{N}=50)$ for each factor were .84 for cognitive, .85 for behavior, .85 for affective and .87 for global attitude. Cronbach's al pha coefficients ( $N=370$ ) for each factor were: .91 for cognitive, .90 for behavior, .89 for affective and .96 for global attitude. All the coefficients values exceed the conventional minimum of .7 (Nunnally and Bernstein 1994) and demonstrate high internal consistency and levels of temporal stability.

Preferred educational setting: To identify the teachers' beliefs on the best educational setting for the students with disabilities, they were asked to choose one of the following settings: a) separate setting (full-time outside the regular school), b) self-contained class (fulltime in special education classrooms in the regular school), c) resource room (part-time in regular classroom with part-time in a resource room), and d) general education (full-time in regular classroom with other support services) 
as the best educational setting for the students with disabilities. These educational settings represent the most segregated setting (a) to the full inclusive educational setting (d).

Gender: This categorical variable involved two levels: Male and female

Teaching Experience: This continuous variable was defined by the number of years the teacher taught.

\section{D ata analysis}

Data was analyzed using IBM SPSS Statistics 20 and IBM Amos 20. Descriptive statistics, chi square, MANOVA, and multiple regressions were performed to analyze the data. In the current study, unlike most of the previous studies, the data relevant to attitudes was analyzed based on the three components of attitudes; these were behavior, cognitive, and affective rather than overall attitudes composite.

\section{RESULTS}

Attitudes towards inclusion: Regular education teachers' attitudes towards inclusion were investigated. The criteria used by De Boer, Pijlb and Minnaerta (2011) were utilized to determine if the attitudes are positive, negative or neutral. The mean score of the items in each component above 2 (on a 3-point $\mathrm{Li}$ kert scale) reflects positive attitudes. The mean score of the items in each component between 1.5 and 2 reflects neutral attitudes. The mean score of the items in each component below 1.5 reflects negative attitudes. The teachers' mean score for each component was 1.90 for the behavior attitudes, 1.83 for the cognitive attitudes, and 1.59 for the affective and suggest that the regular education teachers held neutral behavior, cognitive, and affective attitudes towards inclusion.

Teachers' preference of the educational settings: The regular education teachers' preference of the educational settings for the students with disabilities was examined. The fre quency and percentages of teachers' responses on educational settings preference list were calculated. The results indicated that $48.1 \%$, $33.3 \%, 9.9 \%$, and $8.8 \%$, of the regular education teachers selected separate setting, selfcontained, resource room, and general education respectively as the best educational settings for educating students with disabilities. A chi-square test was performed to determine whether the four educational settings for the students with disabilities were equally se lected by teachers. The selection for the four the educational settings for students with disabilities were not equally distributed in the population, $\chi^{2}(\mathrm{df}=3, \mathrm{~N}=628)=274.89, \mathrm{p}<$ .001 . Moreover, a chi-square test was performed to test the differences between percentages of each pair of educational settings and the results are summarized in Table 2 . These results indicate that the differences between percentage in all pair of educational settings were significant $(p<.001)$, with the exception of differences between the percentage of teachers who believed that the best educational setting was a resource room and the percentages of teachers who believed that the best educational setting was the general education classroom were not significant $(p>.05)$.

Table 2

Results of the chi-square test of the difference between percentages of teachers' responses on education settings prefe-

\begin{tabular}{|c|c|c|c|c|c|c|}
\hline & & & & & & \\
\hline Educational setting & Observed N & Expected $\mathrm{N}$ & Residual & Chi-Square & DF & Asymp.Sig \\
\hline Separate setting & 302 & 255.5 & 46.5 & 16.926 & 1 & .000 \\
\hline Self-contained class & 209 & 255.5 & -46.5 & & & \\
\hline Total & 511 & & & & & \\
\hline Separate setting & 302 & 182.0 & 120.0 & 158.242 & 1 & .000 \\
\hline Resource room & 62 & 182.0 & -120.0 & & & \\
\hline Total & 364 & & & & & \\
\hline Separate setting & 302 & 178.5 & 123.5 & 170.894 & 1 & .000 \\
\hline General education & 55 & 178.5 & -123.5 & & & \\
\hline Total & 357 & & & & & \\
\hline Self-contained class & 209 & 135.5 & 73.5 & 79.738 & 1 & .000 \\
\hline Resource room & 62 & 135.5 & -73.5 & & & \\
\hline Total & 271 & & & & & \\
\hline Self-contained class & 209 & 132.0 & 77.0 & 89.833 & 1 & .000 \\
\hline General education & 55 & 132.0 & -77.0 & & & \\
\hline Total & 264 & & & & & \\
\hline Resource room & 62 & 58.5 & 3.5 & .419 & 1 & .518 \\
\hline General education & 55 & 58.5 & -3.5 & & & \\
\hline Total & 117 & & & & & \\
\hline
\end{tabular}


Effect of teacher's related variables on their attitudes towards inclusion: The effect of teachers' gender and teaching experience on attitudes towards inclusion was examined. A multiple regression was performed using gender (male $=0$, female $=1$ ) and teaching experience (number of years of teaching) as independent variables (predictors) and teachers' attitudes towards inclusion for each attitudes' component as the dependent variable. The results of the three analyses using IBM Amos 20 are summarized in Table 3. These results indicate that teachers' gender and teaching experience had a significant $(p<.05)$ negative relationship with the three attitudes' components, with the exception of teaching experience which did not have a significant impact ( $p>.05)$ on the teachers' cognitive attitudes. Males held significantly more positive attitudes in the three components. Furthermore, teachers' with less teaching experience held more positive behavior and affective attitudes.

Effect of teacher's gender on educational settings preference: A chi-square test was performed to examine the relation between teachers' gender and educational settings preference. The results indicated that there was no significant relationship between teachers' gender and educational settings preference $X^{2}$ $(3, N=628)=.98, p>.05$.

Impact of teachers' educational setting preference on their attitudes towards inclusion: The impact of the regular education teachers' educational settings preference for teaching students with disabilities on their attitudes towards inclusion was examined. Mean and standard deviation scores for each attitude components according to preferred educational settings were calculated and are presented in Table 4. Also, one way betwen groups MANOVA using the independent variable of educational settings preference (separate setting, self-contained, resource room, and general education) was performed on the three dependent variables of cognitive, behavior, and affective response to inclusion. The re sults revealed a significant main effect for educational settings preference, Wilks' Lamb$\mathrm{da}=.89, \mathrm{~F}=8.14$, df $=(9,1511.50), \mathrm{p}<.001$. The univariate $F$ tests showed there were significant effect for the educational settings preference in the three components of attitudes towards inclusion $(p<.01)$. In cognitive $F(3$, $623)=19.44, p<.001$; in behavior $F(3,623)=$ $15.77, p<.01$; and in affective $F(3,623)=19.51$, $p<.001$.

Scheffe post-hoc tests were used to examine the significance of the differences between pair mean scores among educational settings preference levels for every analysis of variance which showed significant main effect (Table 5). These results indicated that the teachers who believed the best educational setting is the general education classroom showed significantly $(P<.05)$ more positive attitudes towards inclusion than the teachers who be lieved the best educational setting is the separate setting and self-contained class in all the three components of attitude. However, there were no significant differences $(P>.05)$ found between teachers who believed the best educational setting was the general education classroom and the teachers who believed the best educational setting was the resource room in all the three components of attitude.

Teachers who believed the best educational setting was the resource room held significantly $(P<.05)$ more positive attitudes towards inclusion than the teachers who believed the best educational setting was the separate setting in the three components of attitude (Table 5). Teachers who believed the best educational setting was the resource room held significantly $(P<.05)$ more positive attitudes towards inclusion than the teachers who believed the best educational setting was the self-contained class only in the affective response to inclusion, whereas the differences were not significant $(P>.05)$ in their behavior response and affective response to inclusion.

Table 3

Results of the multiple regression analyses: gender and teaching experience (predictors) and attitude components (dependent variables)

\begin{tabular}{|c|c|c|c|c|c|}
\hline & & Estimate & S.E. & C.R. & $P$ \\
\hline \multirow{2}{*}{ Behavior } & Gender & -1.987 & .289 & -6.882 & .000 \\
\hline & Teaching Experience & -.113 & .029 & -3.905 & .000 \\
\hline \multirow[t]{2}{*}{ Cognitive } & Gender & -1.029 & .309 & -3.334 & .000 \\
\hline & Teaching Experience & -.049 & .031 & -1.567 & .117 \\
\hline Affective & $\begin{array}{l}\text { Gender } \\
\text { Teaching Experience }\end{array}$ & $\begin{array}{r}-1.261 \\
-.049\end{array}$ & $\begin{array}{l}.213 \\
.021\end{array}$ & $\begin{array}{l}-5.934 \\
-2.295\end{array}$ & $\begin{array}{l}.000 \\
.022\end{array}$ \\
\hline
\end{tabular}


Finally, teachers who believed the best educational setting was the self-contained class in the regular school held significantly $(p<.05)$ more positive attitudes towards inclusion than the teachers who believed the best educational setting was the separate setting in all the three components of attitude (Table 5).

Table 4

M eans and standard deviations for attitude components according to preferred educational setting

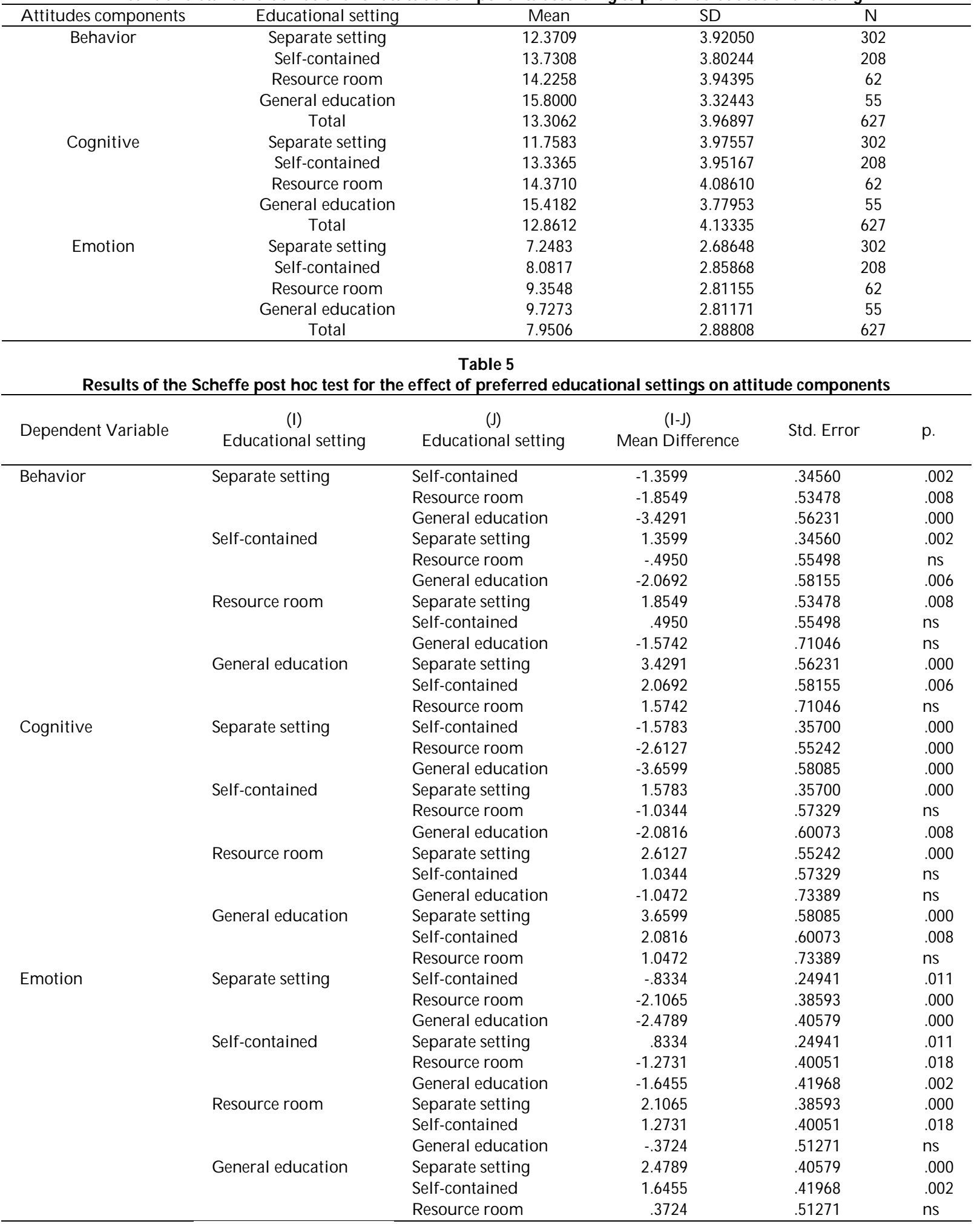




\section{DISCUSSION}

Educational services for children with disabilities are relatively new in Sultanate Oman. Oman has been in the process of reforming its educational system and significant efforts have been made towards achieving this goal. The Ministry of Education in Oman aims to implement inclusive education (Ministry of Education, 2008). Progress has been made as Oman signed the international agreement ensuring the rights of persons with disabilities in education in an inclusive educational setting. Currently the Ministry of Education provides educational services for students with disabilities in special education classes in many public schools as well as in special education schools (Al-Balushi, AlBadi, and Ali, 2011; Weber, 2012).

The literature review revealed that the researchers agreed that the regular education teacher plays a major role in developing and implementing inclusive education. Therefore, assessing the regular education teachers' attitudes towards inclusion in Oman is important.

The regular education teachers' attitudes towards inclusion were investigated. The findings suggest that the regular education teachers held neutral behavior, cognitive, and affective attitudes towards inclusion. De Boer, Pijlb and Minnaerta review of the literature (2011) revealed that teachers showed negative or undecided in their cognitive, affective, and behavior responses to inclusive education. Despite the inconsistency of the previous literature, teachers' attitudes towards inclusion vary cross nations due to cultural values and the level of training of teachers, the number of students receiving services, and the existence of special education within the educational system.

Secondly, teachers' preference of the educational settings for the students with disabilities was examined. The findings revealed the majority of teachers, $81.4 \%$ believed that total segregation (separate setting from regular school: $48.1 \%$ ), or the partial segregation (selfcontained class: $33.3 \%$ ), were the best educational settings for educating students with disabilities. In contrast, only a minority of teachers (18.7\%) believed that full inclusion (regular education: 8.8\%) or partial inclusion (resource room: 9.9\%) were the best educa- tional settings for educating students with disabilities. These results, in general, are consistent with previous research (Scruggs \& Mastropieri, 1996) in which a minority of regular education teachers believed that the general education classroom was the best educational setting to educate students with disabilities. The findings of the current study also revealed that there was no significant re lationship between teachers' gender and educational settings preference.

Thirdly, the effects of the teachers' gender and teaching experience on attitudes towards inclusion were examined. The results indicate that male teachers held significantly more positive attitudes in all three components than female teachers. This finding with re gard to affective attitudes is consistent with Ernst (2006), who reported that male teachers held more positive affective attitudes than female teachers. In contrary to the findings of this study, Ernst (2006) did not find a significant impact due to the teachers' gender on either their cognitive or behavior attitudes. Also, Avramidis, Bayliss, and Burden (2000) did not find a significant impact of teachers' gender on cognitive, affective and behavior attitudes. The literature review of previous studies (De Boer, Pijl, \& Minnaert, 2011, A vramidis \& Norwich, 2002) revealed that findings of the effect of teachers' gender on their attitudes towards inclusion were inconsistent.

Moreover, the results indicate that teachers with less teaching experience held more positive attitudes in behavior and affective attitudes than teachers with more teaching experience, whereas there was no significant relationship $(p>.05)$ between teaching experience and cognitive attitudes. This finding is consistent with the conclusion of De Boer, Pijlb and Minnaerta (2011) that teachers with less years of teaching experience held more positive attitudes towards inclusive education than teachers with many years of teaching experience. However, Avramidis, Bayliss, and Burden (2000), and Ernst (2006) found that teachers' teaching experience had no significant impact on their cognitive, affective, and behavior attitudes. A literature re view by Avramidis and Norwich (2002) re vealed that some researchers reported that teachers' teaching experience had a negative relationship with their attitudes towards in- 
clusion while others reported there was no significant relationship between the two variables.

The results also indicated that the teachers who believed the best educational setting was the resource room held more positive attitudes towards inclusion than the teachers who believed the best educational setting was the self-contained class only in the affective response to inclusion, whereas the differences were not significant $(P>.05)$ in their behavior response and cognitive response to inclusion.

Moreover, the results indicated that the teachers who believed the best educational setting was the self-contained class held more positive attitudes towards inclusion than the teachers who believed the best educational setting was the separate setting in all three components of attitude These findings were expected and predicted. It is logical to hypothesize that the teachers who believed that the best educational setting is general education classroom hold more positive attitudes towards inclusion than the teachers who believed that the best educational setting is the separate setting or self-contained class.

It is worth mentioning that these educational settings (separate setting, self-contained class, resource room, and general education) represent the continuum of special education from the most restrictive educational placement to the least restrictive educational placement.

Implications: The current study identified the regular education teachers' attitudes towards educating students with disabilities in the general education classroom, identified the regular education teachers' preference of the best educational settings for educating students with disabilities, and the influence of teacher's related variables (gender, teaching experience, educational settings preference) on their attitudes towards inclusion. These findings are beneficial for Omani school administrators in planning for the implementation of inclusive education. Finally, the findings of this study add to the limited number of studies based on the conceptualization of attitude as a tri component evaluation consisting of cognitive, affective, and behavioral intention.

Recommendations: Further assessment of Omani teachers' perceived self- efficacy in teaching students with disabilities in the general education classroom; and its impact on their attitudes towards inclusion and educational settings preference are highly recommended.

Limitations: The sample was not selected randomly, but involved regular education teachers from all provinces of Oman who volunteered to participate in this study.

\section{Acknowledgment}

The investigators would like to express their sincere appreciation to the Research Affairs at the Sultan Qaboos University and the United A rab Emirates University for the financial support of this project under Grant \# SQUUAEU/ 09/ 02.

\section{REFERENCES}

Al-Balushi, T., Al-Badi, A., and Ali, S. (2011) Prevalence of disability in Oman: statistics and challenges. Canadian Journal of A pplied Sciences. 1(3), 81-96.

A hsan, T., Sharma, U., \& Deppeler, M., (2012). Exploring pre-service teachers' teachingefficacy, attitudes and concerns about inclusive education in Bangladesh. International Journal of W hole Schooling, 8 (2), 2-20.

A vramidis, E., Balyliss, P., \& Burden, R. (2000). A survey into mainstream teachers' attitudes towards the inclusion of children with special educational needs in the ordinary school in one local education authority. Educational Psychology, 20 (2), 191211.

A vramidis, E., \& Norwich, B. (2002). Teachers' attitudes towards integration/ inclusion: a review of the literature. Eur. J. of Special Education, 17 (2), 129-147.

Bowman, I. (1986). Teacher training and the integration of handicapped pupils: Some findings from a fourteen nation UNESCO study. European Journal of Special Needs Education, 1, 29-38.

Clark, L., \& Watson, D. (1995). Constructing validity: Basic issues in objective scale de velopment. Psychological Assessment, 7, 309-319.

Costello, A., \& Osborne, J. (2005). Best practice in exploratory factor analysis: Four recommendations for getting the most of your analysis. Journal of Practical Assess- 
ment, Research \& Evaluation, 10, 1-9.

De Boer, A., Pijl, S., \& Minnaert, A. (2011). Regular primary school teachers' attitudes towards inclusive education: a review of the literature. International Journal of Inclusive Education, 15(3), 331-353.

De Boer, A., Timmerman, M., Pijl, S., \& Minnaert, A. (20120. The psychometric evaluation of a questionnaire to measure attitudes towards inclusive education. European Journal of Psychology of Education, DOI: 10.1007/ s10212-011-0096-z.

Eagly, A., \& Chaiken, S. (1993). The psychology of attitudes. New York: Harcourt Brace Jovanovich.

Ernst, C. (2006). High school teachers' attitudes towards inclusion of students with special needs. Unpublished doctoral dissertation, University of Rhode Island, Kingston, U.S.A.

Emam, M., \& Hassan, H. (2011). Preschool and primary school teachers' attitudes towards inclusive education in Egypt: the role of experience and self-efficacy. Procedia- Social and Behavioral Sciences, 29, 976-985.

Field, A. (2005). D iscovering statistics using SPSS (2nd). London, England: Sage.

Ford, J., M acCallum, R., \& Tait, M. (1986).The application of exploratory factor analysis in applied psychology: A critical review and analysis. Personnel Psychology, 39, 291314.

Guilford, J. (1954). Psychometric theory (pp. 271-274). New York, NY: McGraw-Hill Book Company, INC.

Ministry of Education. (2008). Inclusive education in the state of 0 man: national report of the Sultanate of O man: Muscat. http:// www.ibe.unesco.org/ National Re ports/ ICE 2008/ oman NR08.pdf

Rafferty, Y., Boettcher, C., and Griffin, K. (2001). Benefits and risks of reverse inclusion for preschoolers with and without disabilities: Parents' perspectives. Journal of Early Intervention 24: 266-86.

Russell, D. (2002). In search of underlying dimensions: The use of (and abuse) of factor analysis in personality and social psychology bulletin. Personality and Social Psychology Bulletin, 28, 1629-1646. DOI: 10.1177/ 01466702237645.

Sari, H., Celikoz, N., \& Secer, Z., (2009). An analysis of preschool teachers' and student teachers' attitudes to inclusion and their self-efficacy. International Journal of Special Education, 24 (3), 29-43.

Scruggs, T., \& Mastropieri, M. A. (1996). Teacher perceptions of mainstreaming/ inclusion, 1958-1995: a research synthesis. Exceptional Children, 63, 59-74.

UNESCO (1990) W orld Declaration on Education for All. Paris, UNESCO.

UNESCO. (1994). The Salamanca statement and the framework for action on special needs education. Paris: UNESCO.

United Nations (2006). Convention on the Rights of Persons with Disabilities and O ptional Protocol. N ew York, United Nations.

Weber, A. (2012). Inclusive education in the gulf cooperation council, Journal of Educational and Instructional Studies in the World, 2 (2), 85-97. 